\title{
A Psychoanalysis of Female Characters in the Novels Heat and Dust and Inside the Haveli: Function of Mother Archetype in the Characters of the Narrator and Geeta
}

\author{
Deepali Jaiswal \\ Ph.D.Scholar \\ Department of English \\ Mahatama Jyotiba Phule Rohilkhand University \\ Bareilly, Uttar Pradesh, India \\ deepalijaiswa1999@gmail.com
}

\begin{abstract}
The psychoanalysts enhance our understanding of our consciousness, the self and selfidentity. Psychoanalytic theory plays an important role in the comprehension of the fundamental condition of selfhood. The self is not an unified entity in psychoanalytical terms. Human subject emerges as an outcrop of the unconscious desire. After Sigmund Freud, Carl Jung, a swiss psychologist is considered as an eminent contributor to psychoanalysis who theorized the concept of collective unconscious. The purpose of my study is to find out the presence of the collective unconscious and to analyse two female characters, The Narrator , from the novel Heat and Dust and Geeta from Inside the Haveli with the help of Jung's theory of collective unconscious and mother archetype. In this research paper several theoretical concepts of Carl Jung are used to analyse the female characters. Jung's theories are applied during the analysis process such as personal conscious, collective conscious and archetypes. I would use qualitative method for the analysis of the characters of the Narrator and Geeta. I would use important dialogues and incidents for the data collection for the analysis of the
\end{abstract}


characters. The psychoanalytic study of the Narrator and Geeta shows that they both have collective unconscious. I would study the function of mother archetype in the life of the Narrator and Geeta

Keywords - Personal Conscious, Collective Unconscious, Archetype, Imagination, GrandMother, Mother-In-Law.

Introduction

According to Jung, the human psyche has two parts --The personal conscious and collective unconscious. The collective unconscious is a layer which does not owe to personal experiences. It cannot be distinguished as personal acquisition. The content of collective conscious owes to those experiences that have been forgotten and repressed with time. One does not acquire these experiences individually rather stores them by heredity. These experiences have never been conscious to him and rest in the deep layer of collective unconscious. Carl Jung says that the collective unconscious is influenced by archetypes. According to Jung our psyche is made up of two spheres. Our immediate conscious is of personal nature. In addition to this empirical psyche, there is a second sphere of collective unconscious which is collective, impersonal, and identical in all human beings. The content of the second layer comes out of the depth into personal conscious only in the moments of crisis and horror.

Problem formulation of this research paper is focused on the analysis of the unconscious mind of The Narrator and Geeta by using Carl Jung's theory of collective unconscious and archetype patterns. I would like to analyse the characters of the Narrator and Geeta by using Jung's archetypal image of 'mother' to find out how far this archetypal image of mother is present in the collective unconscious of the main characters of the selected 
novels. The writer will explain the archetypal images as explained by Carl Jung which are important in order to conduct the analysis:

Carl Jung writes, " there is good reason for supposing that the archetypes are the unconscious images of the instincts themselves, in other words, that they are patterns of instinctual behaviour.', (Jung, vol. 9. p. 44).

Archetypes refer to pre-existent form, a primordial thought. The archetypes are present in human beings everywhere and and always. Archetype can take certain forms that can help a person in everyday psychological needs. Archetypes can be defined as a framework of general situations that are derived from common culture patterns. These archetypes are associated with instincts and ideas. The collective unconscious shows similar imagery regardless of a person's origin, which suggests a universality that belongs to the collective unconscious holistic cultural memories of humanity stored in these often reiterated figures and images. The collective unconscious contains common elements of the collective human experiences despite the fact that it is "invisible". It is not perceived by the conscious mind. Jung emphasized a number of archetypes, which include the 'anima', 'the mother', the 'shadow', the 'child', the 'wise old man', the 'spirits' of fairytales, and the 'trickster' figure found in myths. The two of these are important :

The Anima -

In mythology Anima is expressed as a siren, a wood-nymph, or any female form which sucks life out of young men after infatuating them. When a man idealizes fascinates, infatuates with women, this archetype makes itself present in the life of man.The woman acts as the target to which his anima is transferred. The loss of a relationship can be devastating to a man. 
The Mother -

The mother archetype takes the form of personal mother, grandmother, stepmother, mother-in-law nurse. This form can be fulfilled in figurative mothers like 'Virgin Mary', Sophia, or symbols which include the church, country, the earth, the woods, the sea. This archetype has both positive and negative aspects. Motherly love and care is a positive aspect, and negative aspect can be described as loving mother or the terrible mother. A man who has a mother complex may have high spirits like being tough, preserving, and extremely ambitious.women with mother complex may possess exaggeration of the maternal instinct. She may sacrifice her life and live for her children only. Her husband also is not an important human being in comparison to her children.

By using the novel Heat and Dust and Inside the Haveli, the writer wants to conduct an analysis of the main characters of the novels. The narrator is a character in the novel Heat and Dust who narrates the story in the novel. Heat and Dust is written by Ruth Prawer Jhabwala. The narrator comes to India to search for her grandmother's past life in the country which enlisted before 20 Years. Geeta is the main character in the novel Inside the Haveli who is an educated woman and protagonist of the novel. Inside the Haveli is written by Rama mehata. Geeta is a well educated girl who comes to live in Udaipur after getting married to Ajay.

To analyse the unconscious mind of both the characters, I would apply Carl Jung's theory of mother archetype to them.

\section{Research Method}

The writer's research requires data from the novel in order to conduct the research. The method that will be used for research during the process of the research is the qualitative method. Important words, sentences, incidents, are necessary to conduct the research. The 
sentences from the novel are used as the source of information for the analysis part. The writer expects to be able to have a much deeper understanding of the subject of his research.

\section{Discussion}

In the novel Heat and Dust, the Narrator is an unnamed British woman. She is the step-granddaughter of Olivia Douglas.Olivia was the wife of Douglas. The Narrator writes that she doesn't remember her grandfather at all. He died when she was three years old. She remembers Grandmother Tessie and Great Aunt Beth very well.The narrator tells us that both of them were sensible women. But they could not talk about Olivia for a long time. Her memories were dark and terrible for them. Olivia was a forbidden topic for all. It was not until her parents were old that the two ladies began to talk about Olivia. Olivia's sister Marcia handed Olivia's letters to Harry. He came to see the old ladies and showed them.The narrator brought them with her when she came to India. She comes to India to search for the past life of her grandmother in the country. Olivia had eloped with a prince of Khatam without thinking of the consequences of this act. The Narrator lives in the house of Inder Lal, wears Indian clothes and learns Indian language to communicate to the people. She says, "...this is not my story, it is Olivia's as far as I can follow it.''( Heat and Dust p. 2 .) The Narrator faces the India which is different from the India in which Olivia had lived. But she seems to be a modern counterpart of Olivia in many respects. She lives in Satipur where the whole of Olivia's life took place fifty years ago. She has a relationship with Inder Lal and becomes pregnant. But she is not afraid of the fact rather she decides to give birth to the child. She lives in India at a time when there is no British rule. She can take bold steps and doesn't have to care for her own community.

On the other hand, Geeta is an educated girl who comes from an open atmosphere to live in the traditional atmosphere of the Haveli in Udaipur. She gets married to Ajay, a 
professor, who lives with his parents in Udaipur. When Geeta comes for the first time in the city, she is asked to keep purdah all the time to cover her face. After reaching the Haveli she has to follow the orders of her grandmother. She has to obey her since it is a duty of a daughter in law to do so in Indian society. Geeta's mother also instructs her that she should follow her mother in law in the house of Ajay. Geeta feels completely under her mother in law's control. It can be very well understood from her mother in law's words when she talks to Manji, “But you will agree with me that Biniji should have asked for my permission first doing anything." (Inside. p.118.) Although she wants to protest her on some issues, she keeps silent due to respect. She is not allowed to speak in the presence of her elders. She can't even fondle her own child in front of others. She feels difficult to adjust in the suffocating atmosphere of the Haveli. There are times when Geeta wants to go to her parent's house. After some time her mother in law succeeds in persuading her to adjust in the atmosphere of the Haveli. Ajay tells her about his decision to stay in Udaipur. Geeta feels as if a burden has been removed from her path. She falls into profound sleep because now she knows that she has to spend her rest life in Udaipur.

Point of View

In the novel, Heat and Dust, the story is told in the first person point of view without mentioning the name of the Narrator. The grand - daughter of Olivia Douglas is the narrator of the story who doesn't tell her name to the reader. Through this point of view she tells readers how she feels, reacts to the things that happen to her in India and also how the people around her react to her presence. In the first part of the novel she writes that India changes people and she is not the same as she was when she first came to India, The reader at once connects with the Narrator although he or she knows the story is not about her but rather it is about a search for Olivia's past life in India before twenty years. In the Novel Inside the 
Haveli, the story is told through a third person omniscient point of view. The narrator has an insight into the thoughts, motivations, and actions of all the characters in the story.

The Presence of Mother Archetype in Selected Novels

It is admitted that human activity is influenced by instincts.It is far away from the rational motivations of the personal consciousness. Jung says that a person's imagination, perception, and thinking are influenced by universally present formal elements. it means that these attributes are common to all human beings in general. Jung says that the motif of the dual mother is an archetype to be found in many variants in the field of mythology and religion. It forms the basis of numerous representations collectives. This motif of dual mother, when applied in the case of the Narrator seems to be helpful in finding out the cause of her following the life and history of her grandmother, Olivia. The Narrator seems to be suffering from the delusion that the cause of pursuing Olivia so earnestly lies in her feeling that she really had two mothers ( grand- mother). It is right that she has two mothers if it is personally interpreted -- yet it would be quite wrong. In reality the cause of her search lies in the reactivation of the dual mother archetype regardless of the fact that she has one mother or two mothers. This archetype works individually and historically without any reference to the rare visuality of dual motherhood. This mother motif is so determining power to influence the Narrator to follow after unseen incidents of grandmother's life in India. She is not even conscious of the profound effect of this mother motiff. The Narrator has "active imagination" which increases her unconscious fantasies to perceive the unrealized existence of Olivia's desires and actions in India. The narrator's imagination pushes her to move forward to pursue the dreams, needs, wants, desires and unexpressed thoughts that led Olivia on a bold path. It is the mother motif which leads her to search for the identity and existence of Olivia because she was her grandmother, no matter that she was not her real one. The 
hindrances that checked to speak about Olivia and the letters from Marcia put the Narrator's imagination on fire since she felt it to be her right to know everything about her grandmother. She felt herself connected to her step-grandmother because the mother motif is functioning in her collective unconscious which is shared by every human being in the world.

On the contrary, Geeta is motivated by 'mother image' which has a negative impact on her thoughts and behaviour.The most important mother figures are mother and grandmother, stepmother and mother- in - law. In the novel, mother archetype takes the form of mother-in-law which works in the life of Geeta the protagonist of the novel.The mother archetype in the form of a personal mother works as the loving mother whereas in the form of a mother-in-law it works as the terrible mother. Geeta is haunted by the mother image in the novel which she finds in the form of her grandmother. She knows and is told by her own mother that she should not talk too much before others. The same is instructed to her in the Haveli by her grandmother since it is mandatory for a good daughter-in-law in Indian society. The grandmother is an overpowering authoritative force which works unconsciously on the psyche of a daughter-in-law. She knows that she has to respect and obey her in every circumstance. These manners and etiquettes are taught to every girl since ever the society and marriage institution came into existence. The mother complex in Geeta results in exaggeration of the maternal instinct. She becomes a woman who lives for her children and even sacrifices her own individuality. She makes it her only aim in her life that along with Seeta she has to work for other women's education in the Haveli. Being educated she realizes the fact that an educated girl can speak no to the things that she doesn't want in her life. Only a well educated girl can reject an early marriage proposal. Education becomes a weapon for her to fight against the power and authority practiced by her mother in law in the Haveli. In Indian society the mother archetype is associated with mother-in-law who is considered as a second mother to every daughter in law. The feelings of love and respect felt towards the 
mother in law is due to the function of mother archetype in the collective unconscious which is shared by all human beings. This archetype works awe and terror of mother in law in the minds of girls which is very visible in the behaviour and reactions of Geeta. Jung says that in this sense the archetypal image of mother is nurturing and loving but also capricious, mysterious, and linked to feelings of vulnerability and seduction (Jung 1968).

\section{Conclusion}

Thus, it is clear that there is an intrinsic duality to the archetypal representation of the mother archetype. Carl Jung's view that the archetype originates in the fantasies of individuals is found true in the case of the Narrator in the novel Heat and Dust . It is her intense imagination which gets extremely motivated from dual mother archetype function. She is not even conscious of the activation of this archetype In Inside the Haveli, Geeta is influenced unconsciously by mother archetype working in the form of mother in law since she is a strong figure in an Indian family. It is the function of mother archetype which regulates in her life unconsciously and she surrenders her own individuality. She agrees to flow with the continuous flowing stream of traditions, practices, and culture. It is true that the mother archetype is universal and instinctive and is present in every human being's unconscious sphere. 


\section{Works Cited}

Jhabvala R. P. Heat and Dust, Hind Pocket Books, 1976.

Mehta R ., Inside the Haveli, Penguin Books India ,1996.

Jung, Collected Works vol. 7 (1953), "The Structure of the Unconscious" (1916).

Jung, Collected Works vol. 8 (1960), "The Significance of Constitution and Heredity in Psychology" (1929)

Jung, Collected Works vol. 9.I (1959), "The Concept of the Collective Unconscious", 1936.

Jung, The Archetypes and the Collective Unconscious, London, 1996. C. G. Jung, Man and his Symbols, London, 1978. 